\title{
DEVELOPMENT OF THE QUALITY OF NURSING CARE SCALE FOR HOSPITALISED CHILDREN WITH ACUTE RESPIRATORY INFECTION IN INDONESIA
}

\author{
Dewi Elizadiani Suza,* Busakorn Punthmatharith,** Ladawan Prateepchaikul** \\ *Faculty of Nursing, Universitas Sumatera Utara, Indonesia \\ **Faculty of Nursing, Prince of Songkla University, Thailand \\ Email: Elizadiani@hotmail.com
}

\begin{abstract}
Introduction: Acute respiratory infection in children leads to high morbidity and mortality. This is probably due to a lack of quality of care and no quality control. The Quality of Nursing Care for Hospitalized Ari Children (QNCS-HARIC) instrument is expected to be a potential tool for improving the quality of nursing practice with an approach more genuinely focused on parental involvement, especially in Indonesia. The purpose of this study is to develop a scale of QNCS-HARIC in Indonesia. Methods: Development of the QNCS-HARIC refers to a literature review, expert panel meeting, experts' review, and pilot study. Results: Four dimensions and 79 items were generated: 1) the physical needs of ARI children (36 items); 2) the psychological needs of ARI children and their families (26 items); 3) the socio-cultural needs of ARI children and their families (10 items) and 4) the spiritual needs of ARI children and their families (7 items). The validity was approved by five experts yielding a content validity index equalling .96. After performing the CVI, the QNCS-HARIC consisted of 78 items (deleting 2 items from the dimension on the physical needs of ARI children and an additional 1 item from the dimension on the physical needs of ARI children). The reliability was tested with 30 pediatric nurses yielding an alpha Cronbach's coefficient of the overall QNCS-HARIC 77 items of .94 and each of the dimensions equalled .94, .87, .79, and .73, respectively. Conclusion: To improve the quality of nursing care delivery, pediatric nurses need to be equipped with a quality instrument which should be psychometrically tested, sensitive, specific, accurate, objective, and feasible.
\end{abstract}

Key words: Quality of Nursing Care Scale, Acute Respiratory Infection, Children

\section{INTRODUCTION}

Acute respiratory infection (ARI) is the leading cause in the global burden of diseases (Nair et al. 2013) because of high incidence, substantial morbidity, and potential sequel, a tendency towards over-diagnosis, associated overuse and misuse of antibiotics, and its contribution to health care costs and indirect societal costs (Schaad 2005). The global incidence of ARIs in children is estimated to be 156 million new cases per year of which 151 million episodes occur in developing countries (Rudan, Nair, Marusic \& Campbell 2013).

One to four million deaths occur each year among children with ARI worldwide (Liu et al. 2012). Acute respiratory infections consist of upper and lower respiratory infections, the latter being more commonly found in developing countries (Shafik et al. 2012). The main causes of ARI in children are Streptococcus pneumonia, Haemophilus influenza, as well as the respiratory syncytial virus (Nair et al. 2010).

Acute respiratory infection in children in Indonesia is a serious problem because it leads to high morbidity and mortality. ARI kills more children under five years of age than any other illness in Indonesia (Department of Health
Government of Indonesia 2010). Lower respiratory tract infection is the most commonly found in Indonesia (Wee-Ling 2010). Pneumonia is a common cause of morbidity and mortality among children under five years old (Agustina et al. 2012). The two major diseases causing child mortality from ARI in Indonesia are pneumonia and bronchitis (Lipoeta, Wattanapenpaiboon \& Wahlqvist 2004).

Acute respiratory infection was the major primary cause of death among infants and under-five-year-old children (Affandi \& Utji 2009; Yuliarti, Hadinegoro, Supriyatno \& Karuniawati 2012) and was ranked second as a cause of death amongst infants and children under five years old after diarrhea (Basic Health Research 2007; Faizal 2012). Hernani, Sudarti, Agustina and Sariasih (2009) reported that the trend of incidence rates of acute respiratory infection in children under five from 20042008 decreased but was still high (2004 = $39.91 \%, 2005=27.65 \%, 2006=29.12 \%, 2007$ $=27.71 \%, 2008=22.13 \%)$.

The high incidence of morbidity and mortality of ARI children in Indonesia is probably due to 1) a lack of complete operational procedures for ARI (Hernani, Sudarti, Agustina \& Sariasih 2009) and 2) a low quality of nurse performance (Barber, Gertler \& 
Harimurti 2007). Also, nurses not only face problems of caring for patients with tropical diseases and their families but also have had to adapt to providing care in a system which is beset with difficulties such as shortages of supplies, and inadequate resources (Shields \& Hartati 2003). These possible reasons influence the quality of nursing care for ARI children. In general, the quality of nursing care for sick children with ARI in Indonesia is still far from optimal. This is due to the lack of regulatory standards for education and clinical competence, the absence of proper job descriptions, and also, the training of many nurses does not necessarily match the nature of the work being undertaken (Hennessy, Hicks, Hilan \& Kowanal 2006). Chakraborty and Frick (2002) conducted a study among private hospitals in rural West Bengal, India and focused on providers' disease management practices for acute respiratory infections among under-five children. The study reported inadequate technical quality of care for ARI among the providers which was related to a lack of knowledge (technical incompetence), low levels of performance (limited potential), and inconsistency in performance (within-provider variation).

Indonesia's Health Minister (2010) reported that, in general, quality of care is often lacking and there is no quality control and treatment options are limited. Similar to the study of Lesa and Dixon (2007) in Nigeria, they found an aberration with the clinical training given to nurses in the training institutions largely because of a lack of equipment, lack of continuous training and re-orientation on the job by some employers, lack of commitment on the part of the nurse professionals, and nurses seeing their professional training as just the necessity for registration and licensure. One possible way to reduce the morbidity and mortality of ARI children and increase the quality of nursing care of ARI children is to develop a scale of The Quality of Nursing Care For Hospitalized Ari Children (QNCSHARIC). The scale development will be based on related concepts such as quality of nursing care, holistic care, nursing process, and holistic nursing care for ARI children. The purpose of this study was to develop a scale of QNCSHARIC in Indonesia.

The QNCS-HARIC in this study was developed based on the literature review regarding concepts of quality of nursing care, holistic care, nursing care for ARI children, the nursing process and holistic nursing care for acute respiratory infection children. It was norm referenced and based on an expert panel meeting. The concept of quality of nursing care was defined as the degree to which pediatric nurses provide nursing care based on holistic nursing care to meet the physical, psychological, socio-cultural, and spiritual needs of ARI children and their families.

\section{METHOD}

An inductive methodological design was used to develop an instrument to measure nurse perceptions of quality of nursing care for hospitalised acute respiratory infection (ARI) children. Development of the QNCS-HARIC consisted of 1) determining what is to be measured, 2) generating an item pool, 3) determining the format for measurement, 4) having the initial item pool reviewed by experts, and 5) considering inclusion of validation items (DeVellis 1991). This research has been reviewed for ethical consideration by the Faculty of Nursing, Prince of Songkla University, Thailand (Certificate number: 5110430015).

The sample for the expert panel meeting consisted of pediatric nurses, pediatric nurse lecturers, and pediatricians. Purposive sampling was used to recruit the expert panel who met the inclusion criteria. The participants for the expert panel meeting consisted of four pediatric nurses who provide nursing care to ARI children in the hospital, four pediatric nurse lecturers, and four pediatricians who provide care to ARI children in the hospital. The inclusion criteria consisted of 1) pediatric nurses who have provided nursing care to ARI children for at least six years, 2) pediatric nurse lecturers who have taught nursing care of ARI children for at least six years, and 3) pediatricians who have provided care to ARI children for at least six years. Banner (2001) recommended that six years' experience was the minimum number of years required before being an expert in the field.

The sample for the expert review consisted of two pediatricians who have provided care to ARI children for at least six years, one pediatric nurse who has provided nursing care to ARI children for at least six 
years, and two pediatric nurse lecturers who have taught nursing care of ARI children for at least six years.

The pilot study consisted of 30 pediatric nurses from general hospitals in western Indonesia. Purposive sampling was used to recruit nurses who met the inclusion criteria. The inclusion criteria included pediatric nurses who 1) have provided nursing care to ARI children (aged under five) for at least one year, 2 ) are willing to participate in this study, and 3) can communicate in the Indonesian language.

\section{RESULTS}

The study was based on the literature review regarding the quality of care, the quality of nursing care perspective, the quality of nursing care evaluation, the existing quality of nursing care instruments, the nursing process, holistic care, nursing care for ARI children, and holistic nursing care for ARI children; four dimensions and 80 items of the QNCS-HARIC version 1 were established: 1) physical dimension of ARI children (37 items), 2) psychological dimension of ARI children and their families (26 items), 3) socio-cultural dimension of ARI children and their families (10 items), and 4) spiritual dimension of ARI children and their families (7 items).

The panel of experts consisted of 12 participants from pediatric nurses $(n=4)$, pediatric nurse lecturers $(n=4)$, and pediatricians $(n=4)$. Based on the expert panel meeting, four dimensions and 79 items of the QNCS-HARIC were identified: 1) the physical dimension of ARI children (36 items), 2) the psychological dimension of ARI children and their families (26 items), 3) the socio-cultural dimension of ARI children and their families (10 items), and 4) the spiritual dimension of ARI children and their families (7 items). Only item 14 in the physical dimension of ARI children was deleted because it was redundant, (already contained within item 13). Also, the researcher gave further explanation regarding holistic nursing care and gave an example because some members of the panel of experts did not understand the concepts of holistic nursing care and a nursing care plan.

The content validity of the QNCSHARIC was performed by five experts. The acceptable Content Validity Index (CVI) of the QNCS-HARIC was .96. Two items of the QNCS-HARIC (items 21, 22) were deleted because they were not relevant to nursing care for ARI children. One item (item 34) was added by the experts because they believed that the parents should be instructed to monitor signs of respiratory distress including danger signs at home and when to bring the child to the hospital. Nine items (items 1, 2, 5, 14, 30, 31, 53,67 , and 77) were modified because of a lack of clarity. Sixty-seven items were retained. Thus, after the experts' review, the QNCSHARIC consisted of four dimensions and 78 items: 1) physical dimension of ARI children (35 items), 2) psychological dimension of ARI children and their families (26 items), 3) sociocultural dimension of ARI children and their families (10 items), and 4) spiritual dimension of ARI children and their families (7 items).

The back translation method was used to translate the original English version of the QNCS-HARIC into the Indonesian version (Brislin, 1986). The translation process included forward translation of the development instrument, a blind backtranslation, and comparisons of the original and back-translated version.

Firstly, the original English version of the QNCS-HARIC was translated into the Indonesian language by three nursing experts who were natives of Indonesia and fluent in both English and Indonesian, and also had knowledge of the quality of nursing care with ARI children, instrument development and Indonesian culture. After the translation, the researcher carefully compared and checked for discrepancies among the three questionnaires from the three translators. There were no discrepancies between the three translators.

Secondly, the Indonesian version of the QNCS-HARIC was translated back into English by another three nursing experts native to Indonesia who were fluent in both English and Indonesian. After the back translation, the researcher examined, compared, and checked for discrepancies between the three questionnaires from three translators. There were no discrepancies between the three translators.

Thirdly, an editor who was fluent in English compared the equivalence of two English versions: the original version and the back-translated version. This method was expected to result in equivalence between the original and back translation instrument. The evaluations of semantic equivalence during the translation process indicated that the translated 
Indonesian version of the QNCS-HARIC demonstrated satisfactory semantic equivalence as relative to the English version of the QNCSHARIC through the quality of translation. The original version of the QNCS-HARIC and the back-translated English version were compared. No items were deleted or added at this stage of research. However, the editor made suggestions to change some words or delete items 1, 5, and 12. Item 1: Assess for signs of inadequate oxygen (e.g., cyanotic lip or fingernails, irregular breathing or restlessness, capillary refill $>2$ seconds, hypoxia). The phrase "restlessness" was changed to "difficulty breathing". Item 5: Assess the child's response to activity daily intolerance. The word "daily" was deleted. Item 12: Administer oxygen correctly as prescribed. The phrase "prescribed" was changed to "physician order". In addition, verb tenses were also changed for appropriateness.

The pilot study was conducted with 30 pediatric nurses who had similar qualifications as the study sample from the general hospital, at western Indonesia. The participants' ages ranged from 25 to 48 years. Eighteen of them (60.0\%) were aged more than 40 years old (M = 40.03; $\mathrm{SD}=7.04)$. All participants were female. Twenty-one participants were Christian (70.0\%) and eight were Muslim. Twenty-eight participants were married (93.3\%). All participants had a bachelor degree (100\%). Twenty-six participants (86.7\%) had more than six years of nursing experience $(M=15.13$; $S D$ $=6.74)$. Twenty-six participants $(86.7 \%)$ had more than six years of working experience with acute respiratory infection children ( $M=11.17$; $\mathrm{SD}=5.23)$. Thirteen participants $(43.3 \%)$ took care of ARI children at a rate of fewer than ten cases per month $(\mathrm{M}=8.63$; $\mathrm{SD}=6.43)$.

The results from the pilot study showed that Cronbach's alpha coefficient for overall QNCS-HARIC (78 items) was .94. Cronbach's alpha coefficients for the physical dimension of ARI children, the psychological dimension of ARI children and their families, the sociocultural dimension of ARI children and their families, and the spiritual dimension of ARI children and their families dimensions were .94, .87, .79, and .66, respectively. Since Cronbach's alpha coefficient for the spiritual of ARI children and their families dimension was low $(\mathrm{r}=.66)$ and an item-to-total correlation of item 75 belonging to the spiritual dimension was also low ( $\mathrm{r}=.155)$, it was deleted. After deleting that item, Cronbach's alpha coefficient for the spiritual dimension increased to .73. Overall Cronbach's alpha coefficient for 77 items of the QNCS-HARIC and the physical, psychological, socio-cultural, and spiritual dimensions were $.94, .94, .87, .79$, and .73, respectively.

\section{DISCUSSION}

Many of the criteria considered in developing the QNCS-HARIC were based on three suppositions: 1) the complex, subjective, and multi-dimensional concept of the quality of nursing care makes it difficult to define and measure (Attree 1993, 1996; Hogston 1995b; Idvall \& Rooke 1998; Kunaviktikul et al. 2001; Norman, Redfern, Tomalin \& Oliver 1992), 2) there is a lack of definition and evaluation of the concept of quality of nursing care in children (Leino-Kilpi \& Vuorenheimo 1999; Pelander 2008; Suhonen \& Valimaki 2003), and 3) acute respiratory infection is the major cause of childhood mortality (MDGs-Indonesia 2008).

The components of quality of nursing care for nurses who work with ARI children has not been identified in the nursing literature. Thus, development of components of quality of nursing care for ARI children was based on an extensive review of the literature regarding the quality of nursing care as previously mentioned, the expert panel meeting, and expert review. These four components consisted of 1) the physical dimension of ARI children, 2) the psychological dimension of ARI children and their families, 3) the socio-cultural dimension of ARI children and their families, and 4) the spiritual dimension of ARI children and their families.

This study used DeVellis (1991) as the guideline to develop the QNCS-HARIC. DeVellis's Theory of Scale Development described basic measurement concepts and contains sufficient practical guidance to support construction of a working scale development. There are eight steps in developing the instrument. By using DeVellis's theory, the researcher was guided in the development of the QNCS-HARIC to specify the content domain of the construct, generate an item pool that samples the domain of the QNCS-HARIC, assess the relevance of items through expert review, consider validation items, administer items to a developmental sample, and evaluate items. 
During the research process, the researcher realised that teamwork among the nurses in the expert panels, educational background of the expert reviewers, participation of pediatric nurses, and DeVellis's Theory of Scale Development were the prerequisites for the success of the scale development process of implementation. Plans and strategies set up at every step always involved other parties in the unit to ensure their successful completion. To arrange a meeting among the involved parties was difficult due to limited time. But, with coordination and understanding, the overall process of scale development research was completed and conducted in an appropriate manner.

The QNCS-HARIC was developed based on the quality of nursing care, holistic care, nursing process, and holistic nursing care for ARI children. The philosophy of holism emphasises a sensitive balance between art and science, analytical and intuitive skills, self-care, and the ability to care for patients using the interconnectedness of body, mind and spirit (Dossey 1997). The holistic nursing care of children is a caring activity that focuses on children and families with regard to culture, beliefs and values to meet physical, emotional, mental, spiritual, social and cultural needs (Tjale \& Bruce 2007). Use of holistic nursing care is believed to help pediatric nurses provide nursing care as whole care designed to meet the needs of the whole person (Dossey 1997). The results of the review of the quality of nursing care instrument using holistic nursing care as the conceptual framework showed that there is only one instrument designed for orthopedic adult patients in Taiwan (Lee, Hsu \& Chang 2002). The Orthopedic Nursing Care Quality Monitor Tool (ONCQMT) was used to evaluate the quality of nursing care and compare the quality score based on the plan of nursing care, the physical needs of the patient were attended to, the psycho-social-cultural-spiritual needs of the patient were attended to, and the achievement of nursing care objectives was evaluated.

In similarities, the Quality Patient Care Scale (QUALPACS) was developed by Wandelt and Ager (1974 as cited in Chance 1997). The QUALPACS is designed to measure the quality of nursing care observed by adult patients in any setting in the United States. It consists of physical, psychosocial, general activities, communication, and professional implications. The Rush-Medicus Quality Monitoring Instrument (RMT-MQNC) was developed by Hegyvary and Haussmann (1975 as cited in Chance 1997). The Rush-Medicus Quality Monitoring Instrument consists of the folllowing elements: the plan of nursing care is formulated, the physical needs of the patient are attended to, the psychological, emotional, mental, social needs of the patient are attended to, the achievement of nursing care objectives is evaluated, procedures are followed for the protection of all patients and the delivery of nursing care.

In contrast, the Patient's Assessment of Quality Scale-Acute Care Version (PAQSACV) was developed by Lynn, McMillen and Sidani (2007). The PAQS-ACV is designed to measure the quality of nursing care in acute care units, in the United States. The PAQS-ACV consists of individualisation, nurse character, caring, environment and responsiveness. The Oncology Patients' Perceptions of the Quality of Nursing Care Scale (OPPQNCS) was developed by Radwin, Alster and Rubin (2003). The OPPQNCS is designed to measure the quality of nursing care in New England. The OPPQNCS consists of responsiveness, individualisation, coordination, and proficiency.

When comparing the present instrument with those other instruments, there were some similarities as well as different features. The ONCQMT, QUALPACS and RMT-MQNC showed some similarities in terms of the physical, psychosocial, socio-cultural and spiritual needs, and the plan for nursing care. The ONCQMT was useful to evaluate the quality of nursing care and assist administrators and educators to identify the strengths and weaknesses in the delivery of nursing care. The disadvantage of this instrument was that it did not give an indication of the patient outcome. The QUALPACS results showed a significant improvement in the quality of nursing care with primary nursing practice. However, the fact is that the use of the QUALPACS instrument in a different setting from from that for which it was originally designed could have affected the results (Archibong 1999) and some difficulties are expected if it is used in other countries (Sale 1996). The RMT-MQNC was designed to estimate quality for a nursing unit, but may not be suitable for measurement of differences in care received by individual patients (Fox 1982). 
Furthermore, the PAQS-ACV and OPPQNCS focus on the individualisation, nurse character, caring, environment, responsiveness, coordination and proficiency. Those instruments are not designed to measure quality of nursing care based on the holistic care approach. That instrument was representative for adult patients and developed to measure the quality of nursing care from a patient's perspectives. There is only one study focused on the evaluation of the Child Care Quality at Hospital (CCQH) instrument for hospitalised school-age children (7-11 years) developed in Finland (Pelander, Leino-Kilpi \& Katajisto 2009).

The Rush Medicus Nursing Process Quality Monitoring Instrument (RMI-MSV) was developed by Jelenik et al. (1975 as cited in Chance 1997). The RMI-MSV examined using patient records, patient observation, patient interviews, staff interviews, staff observation, patient environment observation, observer inference and management observation. The RMI-MSV has been translated, modified and tested in several countries. A Swedish version of the RMI-MSV instrument was modified and tested by Gotherstron, Hamrin and Carstensen (1994). The modified Swedish version of the RMIMSV has been tested within surgical, medical, and orthopedic units in a county hospital. The RMI-MSV was found to be sensitive to changes and appropriate for quality assessment.

The QNCS-HARIC instrument was expected to be a potential tool for obtaining knowledge about the quality of pediatric nursing care with ARI children and thereby contributing to improving quality in nursing practice with a more genuinely parental involvement approach, especially in Indonesia. To improve the quality of nursing care delivery, pediatric nurses need to be equipped with a quality instrument which should be psychometrically tested, sensitive, specific, accurate, objective, and feasible.

\section{CONCLUSION}

The results of this study suggest that the newly-developed 77 items of the QNCSHARIC scale is reliable and valid. The reliability was tested with 30 pediatric nurses yielding an alpha Cronbach's coefficient for the overall 77 items of the QNCS-HARIC of .94 and the physical, psychological, socio-cultural, and spiritual dimensions were .94, .87, .79, and .73, respectively. The QNCS-HARIC consisted of four dimensions and 77 items which included: 1) physical dimension of ARI children (35 items), 2) psychological dimension of ARI children and their families (26 items), 3) socio-cultural dimension of ARI children and their families (10 items), and 4) spiritual dimension of ARI children and their families (6 items). There were no reported difficulties encountered during the process of collecting pilot testing data. The average time for a pediatric nurse to complete the pilot testing was approximately 45 to 60 minutes.

The results of the pilot testing supported the readiness for constructing a psychometric evaluation. The use of QNCS-HARIC to evaluate the quality of nursing care will assist administrators and educators in identifying the strengths and weakness in the delivery of nursing care for ARI children.

\section{REFERENCES}

Affandi, N.B. \& Utji, R., 2009. Lower respiratory tract infection in Indonesia with special reference to Harapan Kita Children and Maternity Hospital, Jakarta, viewed 17 January 2010. http://www.tempo.co.id/medika/arsip/ 092002/art-4.htm

Agustina, R., Kok, F.J., de Rest, O.V., Firmansyah, A., Lukito, W., Ferkens, E.M., Bovee-Oudenhoven, I.M., 2012. Randomized trial of probiotics and calcium on diarrhea and respiratory tract infections in Indonesian children. Pediatrics, 5(129), pp. 1155-1164.

Archibong, U.E., 1999. Evaluating the impact of primary nursing practice on the quality of nursing care: A Nigerian study. Journal of Advanced Nursing, 29(3), pp. 680-689.

Attree, M., 1993. An analysis of the concept quality as it relates to contemporary nursing care. International Journal of Nursing Studies, 30(4), pp. 355-369.

Attree, M., 1996. Towards a conceptual model of quality care. International Journal of Nursing Studies, 33, pp. 13-28.

Banner, P., 2001. From novice to expert: Excellence and power in clinical nursing practice. Upper Saddle River, NJ: Prentice Hall. 
Barber, S. L., Gertler, P. J. \& Harimurti, P., 2007. Differences in access to high quality outpatient care in Indonesia. Health Affairs, 26 (3), pp. 352-366.

Basic Health Research, 2007. Indonesia demographic and health survey 2007, viewed 20 March 2010. www.itpbkkbn.org/pulin/004population/004_ID HS_2007_prelim.pdf

Brislin, R.W., 1986. The wording and translation of research instrument. In W.J. Lonner \& J.W. Berry (eds), Field methods in cross-cultural research (pp. 137-164). Beverly Hills, NP: Sage.

Chakraborty, S. \& Frick, K., 2002. Factors influencing private health providers technical quality of care for acute respiratory infections among under five in rural West Bengal, India. Social Science \& Medicine, 55 (9), pp. 15791587.

Chance, K.S., 1997. The quest for quality: An exploration of attempts to define and measure quality nursing care. Image, 128(2), pp. 41-45.

DeVellis, R.F., 1991. Scale development: Theory and applications. Newbury Park, NP: Sage.

Dossey, B.M., 1997. Core curriculum for holistic nursing. Gaithersburg, MD: Aspen.

Faizal, E.B., 2012. Poor skills among health workers blamed for high infant mortality, viewed 10 August 2013.

http://www.thejakartapost.com/news/2012/04/ 21/poor-skills-among-health-workersblamed-high-infant-mortality.html

Fox, R.N. 1982. Measurement of quality of nursing care received by hospitalized surgical patients: Conceptual and methodological sources of variation. New York, NY: Buffalo.

Gotherstron, C., Hamrin, E. \& Carstensen, J., 1994. Testing a modified Swedish version of the Rush Medicus Nursing Process Quality Monitoring Instrument in short-term care. International Journal Quality Health Care, 6 (1), pp. 77-83.

Hennessy, D., Hicks, C., Hilan, A. \& Kowanal, Y., 2006. The training and development needs of nurses in Indonesia: Paper 3 of 3. Human Resources for Health, vol. 4, no. 10, pp. 1-14.

Hernani, Sudarti, Agustina, T. A. \& Sariasih, T., 2009. Report on situation analysis of acute respiratory infection in children in Indonesia, Jakarta, viewed 9 November 2010.

http://files.dcp2.org/pdf/DCP/DCP25.pd $\mathrm{f}$

Hogston, R., 1995b. Quality of nursing care: A qualitative enquiry. Journal of Advanced Nursing, 21, pp. 116-124.

Idvall, E. \& Rooke, L., 1998. Important aspects of nursing care in surgical wards as expressed by nurses. Journal of Clinical Nursing, 7 (6), pp. 512-520.

Indonesian Health Ministry (2010). Quality control, viewed 20 July 2011.

http://www.time.com/time/world/article/ 0,8599,1964611,00.html

Kunaviktikul, W., Anders, R.L., Srisuphan, W., Chontawan, R., Nuntasupawat, R. \& Pumarporn, O., 2001. Development of quality nursing care in Thailand. Journal of Advanced Nursing, 36 (6), pp. 776784.

Lee, L.L., Hsu, N. \& Chang, S.C., 2007. An evaluation of quality of nursing care in orthopedic units. Journal of Orthopaedic Nursing, 11, pp. 160-168.

Leinonen, T. \& Leino-Kilpi, H., 1999. Research in peri-operative nursing care. Review Journal of Clinical Nursing, 8, pp. 123138.

Lesa, R. \& Dixon, A., 2007. Physical assessment implications for nurse educators and nursing practice. International Nursing Review, 54(2), pp. 166-172.

Lipoeta, N.L., Wattanapenpaiboon, N., Malik, A. \& Wahlqvist, M.L., 2004. The nutrition transition in West Sumatra, Indonesia Asia. Pacific Journal Clinical Nutrition, 13 (3), pp. 312-316.

Liu, L., Johnson, H.L., Cousens, S., Perin, J., Scott, S., Lawn, J.E. \& Mathers, C., 2012. Global, regional, and national causes of child mortality: an updated systematic analysis for 2010 with time trends since 2000. The Lancet, 379(9832), pp. 2151-2161.

Lynn, M.R., McMillen, B.J. \& Sidani, S., 2007. Including the provider in the assessment of quality care: Development and testing of the nurses assessment of quality scaleacute care version. Journal of Nursing Care Quality, 22 (4), pp. 328-336.

Millennium Development Goals of Indonesia. (2008). Current situation on MDG 4 and 
5 in Indonesia, viewed 10 April 2010. http://www.targetmdgs.org/download/M DG_Report_2008_En.pdf

Nair, H., Simoes, E.A., Rudan, I., Gessner, B.D., Azziz-Baumgartner, E., Zhang, J.S. \& Feikin, D.R., 2013. Global and regional burden of hospital admissions for severe acute lower respiratory infections in young children in 2010: A systematic analyis. The Lancet, 20(381), pp. 1380-1390.

Norman, I.J., Redfern, S.J., Tomalin, D.A. \& Oliver, S., 1992. Developing Flanagan's critical incident technique to elicit indicators of high and low quality nursing care from patients and their nurses. Journal of Advanced Nursing, 17(5), pp. 590-600.

Pelander, T., 2008. The quality of paediatric nursing care - children's perspective (Doctoral dissertation), viewed 12 December 2010.

https://www.doria.fi/bitstream/handle/

Pelander, T., Leino-Kilpi, H. \& Katajisto, J., 2009. The quality of paediatric nursing care: Developing the Child Care Quality at Hospital instrument for children. Journal of Advanced Nursing, 65(2), pp. 443-453.

Radwin, L.E., Alster, K. \& Rubin, K., 2003. The Development and Psychometric Testing of the Oncology Patient's Perceptions of the Quality of Nursing Care Scale (OPPQNCS). Oncology Nursing Forum, 30, pp. 283290.

Rudan, I., Nair, H., Marusic, A. \& Campbell, H., 2013. Reducing mortality from childhood pneumonia and diarrhoea: The leading priority is also the greatest opportunity. Journal Global Health, 3(1), pp. 1-4.

Schaad, U.B., 2005. Preventions of pediatric respiratory tract infections: Emphasis on the role of OM-85. The European Respiratory Review, 14(95), pp. 74-77.

Shafik, C.F., Mohareb, E.M., Yassin, A.S., Amin, M.A., Kholy, A.E., El-Karaksy, H. \& Youssef, F.G., 2012. Viral etiologies of lower respiratory tract infections among Egyptian children under five years of age. British Medical Journal Infectious Diseases, 12(350), pp. 2-8.

Shields, L. \& Hartati, L. 2003. Nursing and health care in Indonesia. Journal of
Advanced Nursing, vol. 44, no. 2, pp. 209-216.

Suhonen, R. \& Valimaki, M., 2003. Surveying patient satisfaction: Challenging for nursing research. Hong Kong Nursing Journal, 39(2), pp. 7-14.

Tjale, A.A. \& Bruce, J., 2007. A concept analysis of holistic nursing care in paediatric nursing. Curationis, 30(4), pp.45-52.

Wee-Ling, S.S., 2010. Molecular epidemiology of respiratory viruses in a pediatric cohort from Indonesia (Doctoral dissertation), viewed 8 April 2012. http://eprints.qut.edu.au/37309/1/

Yuliarti, K., Hadinegoro, S.R., Supriyatno, B. \& Karuniawati, A., 2012. Invasive pneumococcal disease among hospitalized children aged 28 days to 60 months in Jakarta. Southeast Asian Journal Tropical Public Health, 43, 1, pp.136-144. 